\title{
Assessment of Groundwater Quality Using Water Quality Indices: A Case Study of Paliganj Distributary, Bihar, India
}

\author{
K. Praveen \\ Civil Engineering Department \\ National Institute of Technology Patna \\ Patna, India \\ praveen.ce17@nitp.ac.in
}

\author{
L. B. Roy \\ Civil Engineering Department \\ National Institute of Technology Patna \\ Patna, India \\ lbroy@nitp.ac.in
}

\begin{abstract}
Groundwater quality evaluation in the command area of Paliganj distributary of the Sone irrigation scheme in India was carried out during two different seasons in the year 2020, namely pre-monsoon, i.e. during March, and post-monsoon, i.e. during October. Forty groundwater samples were obtained from hand pumps and dug wells in the study area during the pre- and post-monsoon seasons. The chemical characteristics of groundwater samples were determined according to American Public Health Association approved process. Twelve parameters, namely, pH, EC, TDS, Ca, Mg, Na, F, SO4, K, Cl, and $\mathrm{HCO3}$ were used to compute the water quality based on the weighted arithmetic water quality index method. In the study area, $\mathrm{Ca}^{2+}$ $\mathrm{Mg}^{+}-\mathrm{HCO3}^{-}$, and $\mathrm{Ca}^{2+}-\mathrm{Mg}^{+}-\mathrm{Na}^{+}-\mathrm{HCO3}^{-}$were the dominant hydro-chemical facies. All the samples were found to belong to excellent to good category for drinking purposes during premonsoon period. However, during the post-monsoon season, only $75 \%$ of the samples fell into the excellent to good group, while the remaining $\mathbf{2 5 \%}$ fell into the poor for drinking purposes category. By analyzing through the irrigation quality index, $80 \%$ of the samples are considered highly suitable for irrigation and the remaining $20 \%$ come under the medium category. Thus, it was seen that the majority of groundwater samples are suitable for drinking and irrigation purposes, although groundwater in some portions of the area had high salinity and the Sodium Adsorption Ratio (SAR), showing that it is unsuitable for irrigation and requires adequate drainage.
\end{abstract}

Keywords-chemical parameters; water quality index; weighted arithmetic index; irrigation water quality index

\section{INTRODUCTION}

The pressure on all natural resources to provide enough food and raw materials to meet the demand has increased as a result of the large increase in human population [1]. Drinking and irrigation water supplies will be further stressed. Increased demand may result in substantial changes in the hydrologic cycle, such as a decrease in the groundwater level or a reduction in groundwater quality $[2,3]$. Water in sufficient quantity and of acceptable quality is a fundamental need, yet preserving that quality is difficult. The chemical, physical, and biological characteristics of water are referred to as water quality. If the values of these parameters exceed the stated limitations, they are harmful to human health [4]. Water Quality Index (WQI) is a statistic for expressing the level of water quality in a single numerical statement. It summarizes numerous water quality criteria to determine the acceptability of a water source for drinking purposes. WQI is one of the most effective techniques to quantify water quality. It is commonly used to assess the acceptability of water sources for human consumption. Individual water quality factors have been shown to be difficult to understand when they are used to explain water quality for the general public [5-10].

The weighted arithmetic WQI was first proposed in [11] and further modified in [12]. In general, WQI is a technique for determining water quality conditions, and they, like any other tool, necessitate the understanding of water principles and basic ideas. WQI is a single, dimensionless number that is calculated by combining the major parameters that influence water quality. In general, WQI can avoid the challenges of drawing conclusions from vast amounts of water quality study data. The Irrigation Water Quality (IWQ) concept was implemented by using a model established in [13] to assess the appropriateness of groundwater for irrigation purpose. Authors in [14] investigated uranium and other water quality parameters in drinking water sources in 5 districts of Kerala, southern India, using the WQI method. Groundwater in some cities on the right bank of the river Ganges and in the vicinity of the study area, suffers from TDS, nitrate concentration and fluoride contamination. The result and analysis of the present study shows the current status of groundwater in the study area.

\section{MATERIALS AND METHODS}

A total of 40 groundwater samples were collected from the Paliganj block during March, 2020 (pre-monsoon) and again at the same locations during October 2020 (post-monsoon) to analyze seasonal variation. New, clean $1000 \mathrm{ml}$ polyethylene bottles were used to collect the groundwater samples. At the time of collection, the bottles were thoroughly rinsed 3 times with the same collection of samples. All groundwater samples were taken from hand pumps and dug wells. The groundwater samples were collected from the hand pumps after $5 \mathrm{~min}$ of pumping. This method removes the stored groundwater in the 
well. At the time of sample collection, pH, EC, and TDS readings were measured by a mobile field kit. These factors fluctuate with storage time [15]. The laboratory tests were conducted in the Central Groundwater Board (CGWB), Patna. By using a flame photometer, major cations like sodium and potassium were determined. Thermo-Orion bench top ion electrode was used to determine fluoride and chloride. The total hardness and total alkalinity were determined by titration. The methods and techniques used to analyze all water quality parameters are shown in Table I. The standard procedure given by APHA [16] was used.

TABLE I. METHODS AND TECHNIQUES USED

\begin{tabular}{|c|c|}
\hline Chemical parameter & Method \\
\hline $\mathrm{pH}$ & Mobile $\mathrm{pH}$ meter \\
\hline Electrical Conductivity (EC) & Mobile EC meter \\
\hline Total Dissolved Solids (TDS) & Mobile TDS meter \\
\hline Chloride $\left(\mathrm{Cl}^{-}\right)$ & Ion chromatography \\
\hline Sulphate $\left(\mathrm{SO}_{4}\right)$ & Spectro photometer \\
\hline Nitrate $\left(\mathrm{NO}_{3}{ }^{-}\right)$ & Ion chromatography \\
\hline Calcium $\left(\mathrm{Ca}^{+2}\right)$ & Titration method by using EDTA solution \\
\hline Magnesium $\left(\mathrm{Mg}^{+2}\right)$ & Titration method by using EDTA solution \\
\hline Sodium $\left(\mathrm{Na}^{+}\right)$ & Flame photometer 128 \\
\hline Potassium $\left(\mathrm{K}^{+}\right)$ & Flame photometer 128 \\
\hline Fluoride $\left(\mathrm{F}^{-}\right)$ & Ion chromatography \\
\hline Bicarbonate $\left(\mathrm{HCO}_{3}{ }^{-}\right)$ & Titration method by using $\mathrm{H}_{2} \mathrm{SO}_{4}$ solution \\
\hline
\end{tabular}

\section{A. The Study Area}

The Sone command area aggregate catchment zone of the waterway is $71,259 \mathrm{~km}^{2}$, of which $17,651 \mathrm{~km}^{2}$ lie in Bihar. The remaining $53,608 \mathrm{~km}^{2}$ lie in Chhattisgarh, Madhya Pradesh, Uttar Pradesh, and Jharkhand states of India. The Paliganj Distributary is a part of the Sone Canal System in South Bihar. The Sone River flows north-eastward from the Deccan Plateau before joining the Ganges not far from the city of Patna. The Sone Canal System diverts water from the river to irrigate a design command area of over $700,000 \mathrm{ha}$.

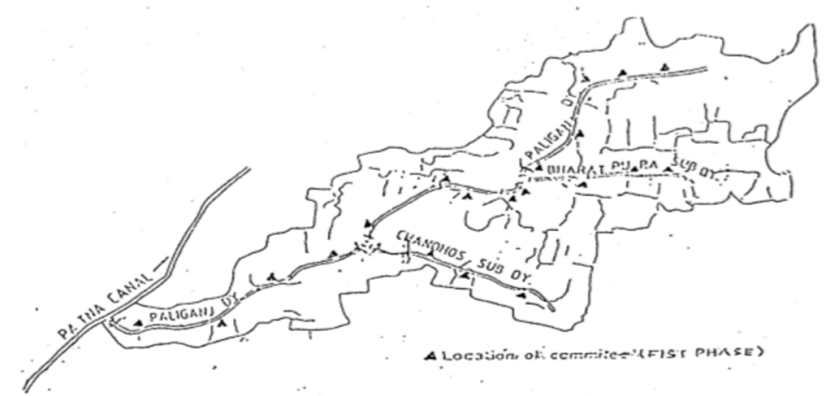

Fig. 1. Index Map of Paliganj Distributary, Sone canal system. (Source: Bihar State Second Irrigation Commission).

\section{B. Water Quality Index Methodology}

The Weighted Arithmetic WQI was used, considering 12 different chemical parameters. The World Health Organization (WHO) and the Bureau of Indian Standards (BIS) established standard values for several water quality indicators as shown in Table II.
TABLE II. CHEMICAL PARAMETERS CONSIDERED FOR WQI, THEIR STANDARD VALUES, AND RECOMMENDING ORGANIZATIONS

\begin{tabular}{|c|c|c|}
\hline $\begin{array}{c}\text { Chemical parameters } \\
\text { (EC- } \boldsymbol{\mu S} \text { /cm, all other } \\
\text { parameters in mg/l) }\end{array}$ & Standard value & $\begin{array}{c}\text { Recommending } \\
\text { organization }\end{array}$ \\
\hline $\mathrm{pH}$ & $6.5-8.5$ & WHO \\
\hline $\mathrm{EC}$ & 400 & WHO \\
\hline $\mathrm{TDS}$ & 500 & WHO \\
\hline $\mathrm{F}^{-}$ & 1 & BIS \\
\hline $\mathrm{HCO}_{3}^{-}$ & 244 & BIS \\
\hline $\mathrm{Ca}^{2+}$ & 75 & BIS \\
\hline $\mathrm{Mg}^{2+}$ & 30 & BIS \\
\hline $\mathrm{NO}_{3}{ }^{-}$ & 300 & BIS \\
\hline $\mathrm{SO}_{4}$ & 45 & BIS \\
\hline $\mathrm{Cl}^{-}$ & 400 & BIS \\
\hline Total & 200 & BIS \\
\hline Total $\mathrm{Alkalinity}(\mathrm{TA})^{2}$ & 200 & BIS \\
\hline
\end{tabular}

The weighted arithmetic index approach [12] was used to calculate the WQI:

$$
\mathrm{WQI}=\left[\frac{\sum Q_{n} \times W_{n}}{\sum W_{n}}\right]
$$

where $W_{n}$ is the unit weight of the $n$th water quality parameter and $Q_{n}$ is its quality rating. Based on the WQI value, the status of water quality is divided into 5 categories, i.e. WQI value between 0 and 25 is Excellent, a value between 26 and 50 comes under Good, a value between 51 to 75 comes under Poor, a value between 76 and 100 comes under Very Poor, and a value above 100 is unsuitable for drinking purposes.

The equation used to compute the quality rating $Q_{n}$ is:

$$
Q_{n}=\left(\frac{V_{n}-V_{i}}{V_{s}-V_{i}}\right) \times 100
$$

where $V_{n}$ is the observed parameter's actual value and $V_{i}$ denotes the parameter's ideal value. Except for $\mathrm{pH}\left(V_{i}=7\right), V_{s}$ is the maximum permitted value for the $n$th water quality parameter.

The formula for calculating $W_{n}$ is:

$$
W_{n}=\frac{k}{V_{s}}
$$

where $k$ is the proportionality constant, which is derived by:

$$
k=\left(\frac{1}{\sum_{V_{S=123 \ldots n} \ldots .}}\right)
$$

\section{Irrigation Water Quality Index Methodology}

IWQ [17, 19] is based on a linear combination of 5 sets of irrigation water quality indicators that have the ability to affect soil quality and crop output significantly. Throughout this method, the 5 groups were analyzed at the same time and then merged to provide a single index value, which is subsequently reviewed to find the suitability of irrigation water. Authors in [18] proposed the guidelines for the selection of water quality parameters given in Tables III and IV. These water quality parameters not only reflect best the related risk, but they also interact with others to form the resource's basic water quality pattern. Moreover, these parameters are set up in such a way that a non-technical policy maker could understand the tool's results and use the procedure without difficulty. 
TABLE III. IWQ INDEX PARAMETER CLASSIFICATION [19]

\begin{tabular}{|c|c|c|c|c|}
\hline Hazard & $\begin{array}{c}\text { Unit } \\
\text { weight }\end{array}$ & $\begin{array}{c}\text { Chemical parameter } \\
\text { range }\end{array}$ & Rating & Suitability \\
\hline \multirow{3}{*}{ Salinity } & \multirow{3}{*}{5} & $\mathrm{EC}>3,000$ & 1 & Low \\
\hline & & $700 \leq \mathrm{EC} \leq 3,000$ & 2 & Medium \\
\hline & & $\mathrm{EC}<700$ & 3 & High \\
\hline $\begin{array}{l}\text { Infiltration } \\
\text { and } \\
\text { permeability }\end{array}$ & 4 & \multicolumn{3}{|c|}{ Details are given in Table IV } \\
\hline \multirow{9}{*}{$\begin{array}{l}\text { Specific ion } \\
\text { toxicity }\end{array}$} & \multirow{9}{*}{3} & $\mathrm{SAR}>9$ & 1 & Low \\
\hline & & $3.0 \leq \mathrm{SAR} \leq 9.0$ & 2 & Medium \\
\hline & & $\mathrm{SAR}<3$ & 3 & High \\
\hline & & $\mathrm{B}<0.7$ & 3 & High \\
\hline & & $0.7 \leq \mathrm{B} \leq 3.0$ & 2 & Medium \\
\hline & & $\mathrm{B}>3.0$ & 1 & Low \\
\hline & & $\mathrm{CI}<140$ & 3 & High \\
\hline & & $140 \leq \mathrm{CI} \leq 350$ & 2 & Medium \\
\hline & & $\mathrm{CI}>350$ & 1 & Low \\
\hline $\begin{array}{l}\text { Trace } \\
\text { element } \\
\text { toxicity }\end{array}$ & 2 & \multicolumn{3}{|c|}{ Details are given in Table $\mathrm{V}$} \\
\hline \multirow{9}{*}{$\begin{array}{l}\text { Effects on } \\
\text { sensitive } \\
\text { crops }\end{array}$} & \multirow{9}{*}{1} & $\mathrm{NO}_{3}<5.0$ & 3 & High \\
\hline & & $5.0 \leq \mathrm{NO}_{3} \leq 30.0$ & 2 & Medium \\
\hline & & $\mathrm{NO}_{3}>30.0$ & 1 & Low \\
\hline & & $\mathrm{HCO}_{3}<90$ & 3 & High \\
\hline & & $90 \leq \mathrm{HCO}_{3} \leq 500$ & 2 & Medium \\
\hline & & $\mathrm{HCO}_{3}>500$ & 1 & Low \\
\hline & & $\mathrm{pH}<6.5$ or $\mathrm{pH}>8.5$ & 1 & Low \\
\hline & & $\begin{array}{c}6.5 \leq \mathrm{pH}<7.0 \text { and } \\
8.0<\mathrm{pH} \leq 8.5\end{array}$ & 2 & Medium \\
\hline & & $7 \leq \mathrm{pH} \leq 8$ & 3 & High \\
\hline
\end{tabular}

IWQ index $=\sum_{i=1}^{5} G_{i}$

where $G$ represents the contribution of each of the five risk factors that are important in determining the irrigation system's quality and $i$ represents the incremental index. The salinity is the first considered parameter:

$$
G_{1}=w_{1} \times r_{1}
$$

where $w$ is the hazard group's weight value and $r$ represent the parameter's rating value, as shown in Table III.

The permeability hazard and infiltration, which is represented by the EC - SAR combination and is formulated as:

$$
G_{2}=w_{2} \times r_{2}
$$

where $w$ is the weight value, and $r$ represents the parameter's rating value as shown in Table IV. The third category is specific ion toxicity, which is defined as a weighted average of the three ions in water (SAR, chloride, and boron ions):

$$
G_{3}=\frac{w_{3}}{3} \sum_{j=1}^{3} r_{j}
$$

where $j$ represents an incremental index, $w$ is the group's weight value as shown in Table IV, and $r$ represents each parameter's rating value as shown in Table IV.

The trace element toxicity category is calculated as the weighted average of all the ions available for analysis:

$$
G_{4}=\frac{w_{4}}{N} \sum_{k=1}^{N} r_{k}
$$

where $w$ is the group's weight and $N$ is the total number of trace elements that can be analyzed. As shown in Table V, $k$ is the incremental index, and $r$ represents the rating value of each parameter.

The 5th and final category is the weighted average of several influences on sensitive crops, which are represented by $\mathrm{NO}_{3}{ }^{-}$and $\mathrm{HCO}_{3}{ }^{-}$ions, and the $\mathrm{pH}$ of water.

$$
G_{5}=\frac{w_{5}}{3} \sum_{l=1}^{3} r_{l}
$$

where $l$ represents the incremental index, $w$ represents the group's weight value, and $r$ is each parameter's rating value, as shown in Table III.

TABLE IV. INFILTRATION AND PERMEABILITY HAZARD CLASSIFICATION [19]

\begin{tabular}{|c|c|c|c|c|c|c|c|}
\hline & \multicolumn{5}{|c|}{ SAR } & \multirow{2}{*}{ Rating } & \multirow{2}{*}{ Suitability } \\
\hline \multirow{4}{*}{ EC } & $<3$ & $3-6$ & $6-12$ & $12-20$ & $>20$ & & Low \\
\cline { 2 - 8 } & $<200$ & $<300$ & $<500$ & $<1300$ & $<2900$ & 3 & \multirow{2}{*}{\begin{tabular}{l} 
Medium \\
\cline { 2 - 8 }
\end{tabular}} \\
\cline { 2 - 8 } & $>700-200$ & $\begin{array}{c}1200- \\
300\end{array}$ & $\begin{array}{c}1900- \\
500\end{array}$ & $\begin{array}{c}2900- \\
1300\end{array}$ & $\begin{array}{c}5000- \\
2900\end{array}$ & 2 & High \\
\hline
\end{tabular}

TABLE V. TOXICITY CLASSIFICATION

\begin{tabular}{|c|c|c|c|}
\hline Factor & Range & Rating & Suitability \\
\hline \multirow{3}{*}{ Fluoride $(\mathrm{mg} / \mathrm{l})$} & $\mathrm{F}>15$ & 1 & Low \\
\cline { 2 - 4 } & $1.0 \leq \mathrm{F} \leq 15.0$ & 2 & Medium \\
\cline { 2 - 4 } & $\mathrm{F}<1$ & 3 & High \\
\hline
\end{tabular}

TABLE VI. IWQ INDEX CLASSIFICATION

\begin{tabular}{|c|c|}
\hline IWQ Index & Water suitability for irrigation \\
\hline$<22$ & Low \\
\hline $22-37$ & Medium \\
\hline$>37$ & High \\
\hline
\end{tabular}

For the computation of the index's total value, suitability analysis has been performed using the 3 categories listed in Table VI. The values in the Table were derived by providing different rating factors (i.e. 1, 2, and 3) to each parameter while keeping the weighted coefficient constant, resulting in 3 different index values. The upper and lower limits for each category in Table VI are determined by the medians of these values.

\section{RESULTS AND DISCUSSION}

The current study involves the estimation of WQI for water samples obtained from 20 sampling locations during pre- and post-monsoon season. A total of 40 groundwater samples of WQI were considered and the weighted arithmetic index method was used. The results are shown in Figure 2. The methods that were employed in the analysis of various water chemical parameters are given in Table I. Table VII shows the calculated SAR values of the study area. It should be noted that the SAR value of four locations is more than 10 , which indicates salinity hazard, requiring adequate drainage. The different water quality parameters were compared to the international standards recommended by WHO $[15,20]$ and BIS-2012 [21] (Table VIII).

After analyzing the water quality index during the premonsoon season, $35 \%$ of the samples came under the Excellent 
category and the remaining $65 \%$ under the Good category for drinking purposes. During the post-monsoon season, $15 \%$ of the samples come under the Excellent category, $60 \%$ under the Good category, and the remaining 25\% are Poor to Very Poor.

TABLE VII. CALCULATED SAR VALUES OF THE STUDY AREA

\begin{tabular}{|c|c|c|}
\hline \multirow{2}{*}{ Location } & Pre-monsoon & Post-monsoon \\
\cline { 2 - 3 } & SAR & SAR \\
\hline Paipura & 5.4 & 2.5 \\
\hline Fathepur & 5 & 2.6 \\
\hline Kurkuri & 3.1 & 2.6 \\
\hline Sarsi & 2.7 & 3.1 \\
\hline Shiyarampur & 2.8 & 5.6 \\
\hline Bara & 3 & 2.4 \\
\hline Satpura & 3.2 & 2.6 \\
\hline Pipardah & 2.7 & 8.8 \\
\hline Lalganj & 10.5 & 4.4 \\
\hline Gulitar & 11 & 7.8 \\
\hline Makmilpur & 10.2 & 4.1 \\
\hline Baratpura & 3.4 & 11.2 \\
\hline Achhua & 17.4 & 12.3 \\
\hline Dulhin Bazar & 2.8 & 11.1 \\
\hline Ular Pond & 8.4 & 6.1 \\
\hline BhimniChak & 3.2 & 6.4 \\
\hline Harpura & 3.2 & 4.3 \\
\hline Nabi Nagar & 4.6 & 2.7 \\
\hline Aktiyarpur & 2 & 6.6 \\
\hline Khapura & 3.5 & 5 \\
\hline
\end{tabular}

TABLE VIII. INTERNATIONAL STANDARDS USED TO COMPARE VARIOUS WATER QUALITY PARAMETERS

\begin{tabular}{|c|c|c|c|c|c|}
\hline \multirow{2}{*}{ Parameter } & \multirow{2}{*}{$\begin{array}{c}\text { WHO/BIS } \\
\text {-limit }\end{array}$} & $\begin{array}{c}\text { Pre-monsoon } \\
\text { No. of } \\
\text { samples }\end{array}$ & $\begin{array}{c}\text { \%o of } \\
\text { samples } \\
\text { exceeded }\end{array}$ & $\begin{array}{c}\text { Po. of } \\
\text { samples }\end{array}$ & $\begin{array}{c}\text { \% of } \\
\text { samples } \\
\text { exceeded }\end{array}$ \\
\hline $\mathrm{pH}$ & $6.5-8.5$ & 20 & 0 & 20 & 0 \\
\hline $\mathrm{EC}$ & 400 & 20 & 65 & 20 & 60 \\
\hline $\mathrm{TDS}$ & 500 & 20 & 20 & 20 & 15 \\
\hline $\mathrm{F}^{-}$ & 1 & 20 & 0 & 20 & 0 \\
\hline $\mathrm{Cl}^{-}$ & 250 & 20 & 0 & 20 & 0 \\
\hline $\mathrm{HCO}_{3}$ & 244 & 20 & 50 & 20 & 45 \\
\hline $\mathrm{SO}_{4}$ & 400 & 20 & 0 & 20 & 0 \\
\hline $\mathrm{NO}_{3}^{-}$ & 45 & 20 & 10 & 20 & 0 \\
\hline $\mathrm{Ca}^{+2}$ & 75 & 20 & 5 & 20 & 5 \\
\hline $\mathrm{Mg}^{+2}$ & 30 & 20 & 20 & 20 & 10 \\
\hline $\mathrm{TA}^{-2}$ & 200 & 20 & 70 & 20 & 55 \\
\hline $\mathrm{TH}^{2}$ & 200 & 20 & 35 & 20 & 25 \\
\hline
\end{tabular}

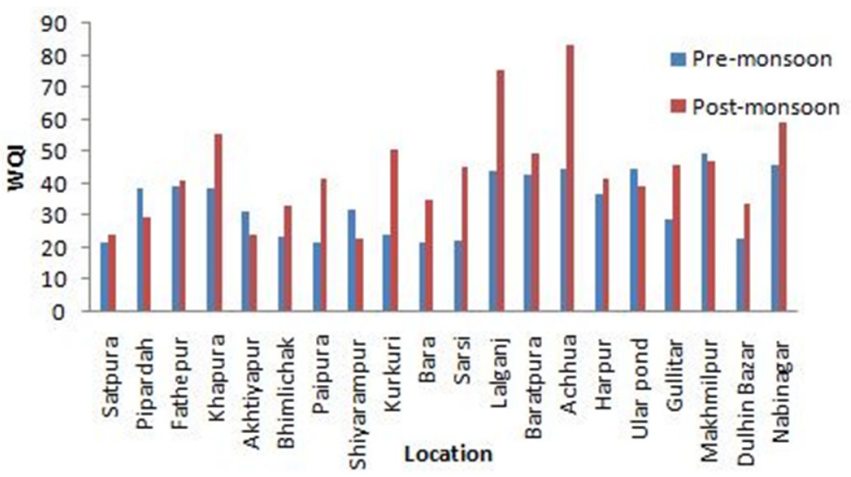

Fig. 2. Pre- and post- monsoon WQIs.
IWQ index [13] was used for groundwater assessment for irrigation purposes in the command area of Paliganj Distributary of the Sone Irrigation scheme in India. By analyzing the groundwater samples showed in Table IX with the IWQ index, $80 \%$ of the samples came under the Highly suitable for irrigation purposes category and the remaining 20\% under the Medium suitable category. Therefore, overall, all groundwater samples in the study area are considered suitable for irrigation purposes, but some areas have high sodium percentage and SAR value, indicating irrigation unsuitability. Therefore, adequate drainage is required to overcome this problem.

TABLE IX. IWQ INDEX WITH IRRIGATION WATER STATUS IN THE STUDY AREA

\begin{tabular}{|c|c|c|c|c|c|c|c|}
\hline Location & G-1 & G-2 & G-3 & G-4 & G-5 & IWQ & $\begin{array}{c}\text { Status of water } \\
\text { for irrigation }\end{array}$ \\
\hline Paipura & 15 & 4 & 18 & 6 & 1.98 & 44.98 & High \\
\hline Fathepur & 15 & 4 & 12 & 6 & 2.31 & 39.31 & High \\
\hline Kurkuri & 15 & 8 & 18 & 6 & 2.31 & 49.31 & High \\
\hline Sarsi & 15 & 4 & 18 & 6 & 2.31 & 45.31 & High \\
\hline Shiyarampur & 15 & 8 & 18 & 6 & 2.31 & 49.31 & High \\
\hline Bara & 15 & 8 & 18 & 6 & 1.98 & 48.98 & High \\
\hline Satpura & 15 & 8 & 18 & 6 & 1.98 & 48.98 & High \\
\hline Pipardah & 15 & 8 & 27 & 6 & 2.64 & 58.64 & High \\
\hline Lalganj & 10 & 8 & 9 & 6 & 2.31 & 35.31 & Medium \\
\hline Gulitar & 10 & 8 & 9 & 6 & 1.65 & 34.65 & Medium \\
\hline Makmilpur & 10 & 8 & 9 & 6 & 1.65 & 34.65 & Medium \\
\hline Baratpura & 15 & 8 & 12 & 6 & 2.31 & 43.31 & High \\
\hline Achhua & 15 & 4 & 6 & 6 & 2.64 & 33.64 & Medium \\
\hline Dulhin Bazar & 10 & 12 & 27 & 6 & 1.98 & 56.98 & High \\
\hline Ular Pond & 15 & 8 & 12 & 6 & 2.31 & 43.31 & High \\
\hline BhimniChak & 15 & 8 & 12 & 6 & 2.31 & 43.31 & High \\
\hline Harpura & 15 & 8 & 12 & 6 & 2.31 & 43.31 & High \\
\hline Nabi Nagar & 15 & 8 & 12 & 6 & 2.31 & 43.31 & High \\
\hline Aktiyarpur & 15 & 8 & 18 & 6 & 2.31 & 49.31 & High \\
\hline Khapura & 15 & 4 & 18 & 6 & 2.64 & 45.64 & High \\
\hline
\end{tabular}

\section{RESULT COMPARISON}

Authors in [22] analyzed groundwater samples from 14 different stations of Patna city based on WQI and the results placed the water in the Good category. However, none of their samples was found suitable for drinking purposes as they were all found to have high concentration of total and fecal coliform. Also, they found that TDS and nitrate concentration at some locations were above the standards' limits for drinking water. Authors in [23] studied groundwater quality for samples collected from different locations of Sabour block in Bhagalpur district, Bihar using WQI. They found that around 7\% of the samples had WQI score greater than 100, the limit for drinking water. Based on this, they suggested water safety and remediation measures.

\section{CONCLUSIONS}

The WQI is a single value calculated from a set of water quality parameters that can be used to determine the quality and drinkability of a water sample. WQI estimation can help us save time and effort while dealing with groundwater data. It can also facilitate to communicate the data-driven decision with only one value. By analyzing WQI through the weighted arithmetic index method, during the pre-monsoon season, all 
samples were either excellent or good for drinking purposes. However, during the post-monsoon season, only $75 \%$ of the samples fell into the excellent to good range, while the remaining $25 \%$ fell were poor to extremely poor. By analyzing the samples through the IWQ index, $80 \%$ of them fell in the highly recommended for irrigation category and $20 \%$ were medium suitable for irrigation purposes. Therefore, the overall groundwater quality is considered satisfying with respect to the standard values given by WHO and BIS, but in some parts of the study area the groundwater has high salinity and SAR, indicating that it is unsuitable for irrigation and requires adequate drainage. A collaborative multi-agency approach is recommended in order to ensure that agencies responsible for the study area are involved in the management of water quality. The outcome of this study may be used for the effective monitoring of water quality for drinking and irrigation purposes in the study area and elsewhere in the state and the country.

\section{REFERENCES}

[1] V. Smil, Long-Range Perspectives on Inorganic Fertilizers in Global Agriculture 1999 Travis P. Hignett Lecture. Muscle Shoals, AL, USA: International Fertilizer Development Center, 1999.

[2] Guide Manual: Water and Wastewater Analysis. New Delhi, India: Central Pollution Control Board, 2013.

[3] L. F. Konikow and E. Kendy, "Groundwater depletion: A global problem," Hydrogeology Journal, vol. 13, no. 1, pp. 317-320, Nov. 2005, https://doi.org/10.1007/s10040-004-0411-8.

[4] N. Diersing, Water Quality: Frequently asked questions. Florida Keys, FL, USA: Florida Keys National Marine Sanctuary, 2009.

[5] A. Banerjee, P. Singh, and K. Pratap, "Hydrogeological component assessment for water resources management of semi-arid region: a case study of Gwalior, M.P., India," Arabian Journal of Geosciences, vol. 9 , no. 18, Aug. 2016, Art. no. 711, https://doi.org/10.1007/s12517-0162736-8.

[6] I. Akoteyon, A. Omotayo, O. Soladoye, and H. O. Olaoye, "Determination of water quality index and suitability of Urban River for municipal water supply in Lagos-Nigeria," European Journal of Scientific Research, vol. 54, no. 2, pp. 263-271, Mar. 2011.

[7] M. Atikul Islam et al., "Investigation of Groundwater Quality and Its Suitability for Drinking and Agricultural Use in the South Central Part of the Coastal Region in Bangladesh," Exposure and Health, vol. 9, no. 1, pp. 27-41, Nov. 2017, https://doi.org/10.1007/s12403-016-0220-z.

[8] N. Bharti and D. Katyal, "Water Quality Indices Used for Surface Water Vulnerability Assessment," International Journal of Environmental Sciences, vol. 2, no. 1, pp. 154-173, Sep. 2011.

[9] L. Nhamo et al., "An assessment of groundwater use in irrigated agriculture using multi-spectral remote sensing," Physics and Chemistry of the Earth, vol. 115, Nov. 2020, Art. no. 102810, https://doi.org/ 10.1016/j.pce.2019.102810.

[10] M. A. Keerio, N. Bhatti, S. R. Samo, A. Saand, and A. A. Bhuriro, "Ground Water Quality Assessment of Daur Taluka, Shaheed Benazir Abad," Engineering, Technology \& Applied Science Research, vol. 8, no. 2, pp. 2785-2789, Apr. 2018, https://doi.org/10.48084/etasr.1925.

[11] R. K. Horton, "An Index Number System for Rating Water Quality," Journal of the Water Pollution Control Federation, vol. 37, pp. 300$306,1965$.

[12] R. M. Brown, N. I. McClellan, R. A. Deininger, and R. G. Tozer, "A water quality index-do we dare," Water and Sewage Works, vol. 117, no. $10,1970$.

[13] A. C. M. Meireles, E. M. de Andrade, L. C. G. Chaves, H. Frischkorn, and L. A. Crisostomo, "A new proposal of the classification of irrigation water," Revista Ciência Agronômica, vol. 41, pp. 349-357, Sep. 2010, https://doi.org/10.1590/S1806-66902010000300005.

[14] C. S. Shalumon et al., "Analysis of uranium and other water quality parameters in drinking water sources of 5 districts of Kerala in southern
India and potability estimation using water quality indexing method," HydroResearch, vol. 4, pp. 38-46, Jan. 2021, https://doi.org/10.1016/ j.hydres.2021.04.003.

[15] Guidelines for drinking-water quality, 2nd ed. Geneva, Switzerland: WHO, 1993.

[16] Standard Methods for the Examination of Water and Wastewater, 20th ed., Washington DC, USA: American Public Health Association/ American Water Works Association, 1998, pp. 235-237.

[17] N. Kumar, A. A. Mahessar, S. A. Memon, K. Ansari, and A. L. Qureshi, "Impact Assessment of Groundwater Quality using WQI and Geospatial tools: A Case Study of Islamkot, Tharparkar, Pakistan," Engineering, Technology \& Applied Science Research, vol. 10, no. 1, pp. 5288-5294, Feb. 2020, https://doi.org/10.48084/etasr.3289.

[18] R. S. Ayers and D. W. Westcot, Water quality for agriculture. Rome, Italy: Food and Agriculture Organization, 1985.

[19] C. Simsek and O. Gunduz, "IWQ Index: A GIS-Integrated Technique to Assess Irrigation Water Quality," Environmental Monitoring and Assessment, vol. 128, no. 1, pp. 277-300, Feb. 2007, https://doi.org/ 10.1007/s10661-006-9312-8.

[20] A. N. Laghari, Z. A. Siyal, D. K. Bangwar, M. A. Soomro, G. D. Walasai, and F. A. Shaikh, "Groundwater Quality Analysis for Human Consumption: A Case Study of Sukkur City, Pakistan," Engineering, Technology \& Applied Science Research, vol. 8, no. 1, pp. 2616-2620, Feb. 2018, https://doi.org/10.48084/etasr.1768.

[21] BIS: 10500. Indian Standard. Driniking Water-Specification. BIS, 2012.

[22] D. Sukumaran, R .Saha, and R. C. Saxena, "Ground Water Quality Index of Patna, the Capital City of Bihar, India," American Journal of Water Resources, vol. 3, no. 1, pp. 17-21, Oct. 2015, https://doi.org/10.12691/ ajwr-3-1-3.

[23] D. Verma, J. Mandal, R. Padbhushan, S. Kumar, and M. Lal, "Water quality index for the assessment of groundwater quality in the Sabour block of Bhagalpur district, Bihar," International Journal of Agriculture, Environment and Biotechnology, vol. 9, no. 4, pp. 467-472, May 2016, https://doi.org/10.5958/2230-732X.2016.00061.9. 